\title{
Binding of Metallothionein to Rat Spermatozoa
}

\author{
Takanori Suzuki, Katsuyuki Nakajima*, Akiko \\ Yamamoto, KeiJi Suzuki $\dagger$, KoJi Yamamoto $\ddagger$ and \\ Hidetoshi Yamanaka
}

Department of Urology, School of Medicine, Gunma University, Maebashi 371, *Japan Immunoresearch Laboratories Co., Ltd., Takasaki 370, †Department of Pathology, College of Medical Care and Technology, Gunma University, Maebashi 371 and $\ddagger$ Otsuka Pharmaceutical Co., Ltd., Tokushima 770

Suzuki, T., Nakajima, K., Yamamoto, A., Suzuki, K., Yamamoto, K. and Yamanaka, H. Binding of Metallothionein to Rat Spermatozoa. Tohoku J. Exp. Med., 1994, 174 (1), 19-30 — Binding studies of metallothionein and rat spermatozoa were performed using ${ }^{125} \mathrm{I}$-Tyr-metallothionein $\left({ }^{125} \mathrm{I}-\mathrm{MT}\right)$. Reactions between ${ }^{125} \mathrm{I}-\mathrm{MT}$ and spermatozoa indicated that MT bound in two forms, namely, middle affinity $\left(\mathrm{Kd} 1=2 \times 10^{-9} \mathrm{M}\right)$ binding and low affinity $\left(\mathrm{Kd} 2=1 \times 10^{-8} \mathrm{M}\right)$ binding. Labeled MT binding to spermatozoa was inhibited by adding anti-MT antibody. Total binding reactions of MT were temperature and incubation time dependent. By transmission electron microscopy using a gold conjugate (indirect method), gold particles bound to MT were shown to bind to the cell membrane of the head and the proximal portion of the tail. By optical autoradiography, grains of labeled MT were localized mainly in the head and the proximal portion of the tail. By electron microscopical autoradiography, grains of labeled MT were identified mainly in the cell membrane of the head and tail and partly in the nucleus. These results suggest that MT has both specific and non-specific binding sites on the spermatozoal membrane. - metallothionein (MT); spermatozoa; autoradiography; transmission electron microscopy

Metallothionein (MT) is a metal-binding protein with a low molecular weight of approximately 6,000 and with high cysteine and sulfur content (Margoshes and Vallee 1957). It has been identified in a variety of organs, including the prostate (Waalkes et al. 1982; Bataineh et al. 1986; Umeyama et al. 1987; Suzuki et al. 1991), and binds class II-B metals, such as cadmium and zinc. Zinc is concentrated in the prostatic tissue and secreted into prostatic fluid (Mawson and Fisher

Received February 15, 1994; revision accepted for publication July 23, 1994.

Address for reprints: Dr. Takanori Suzuki, Department of Urology, School of Medicine, Gunma University, 3-39-22 Showa-machi, Maebashi, Gunma 371, Japan.

A part of this study was presented at the third International Conference on Metallothionein in Tsukuba in December, 1992. 
1952). Also, zinc interacts with spermatozoa and is involved in sperm motility and viability (Marmar et al. 1975). Recently we have reported about the localization and function of MT in rat and human prostatic tissue and shown its secretion into prostatic fluid by radioimmunoassay (Suzuki et al. 1991, 1992). This result suggested that MT in the prostatic fluid which is secreted from the prostatic epithelial cells, has some biological function for the spermatozoa. However, the role of MT in the male genital organs remained unclear, and this study was conducted to clarify the relationship between MT and the epididymal spermatozoa of the rat.

\section{Materials and Methods}

\section{Animal and preparation of the spermatozoa}

Adult male Wistar rats (age 12-15 weeks) were purchased from Imai Experimental Animals (Saitama). After rats were anesthetized with ether, the abdominal wall was incised in the midline, and testis, epididymis and spermatic cord were removed from the scrotum. The tail portion of epididymis was pressed by finger and the spermatozoa removed from the tail portion of epididymis. The spermatozoa were immediately added to sperm-Ringer solution $(0.9 \% \mathrm{NaCl} 100 \mathrm{ml}, 1.15 \%$ $\mathrm{KCl} 4 \mathrm{ml}, 2.11 \% \mathrm{KH}_{2} \mathrm{PO}_{4} 1 \mathrm{ml}, 3.82 \% \mathrm{MgSO}_{4} \cdot 7 \mathrm{H}_{2} \mathrm{O} 1 \mathrm{ml}, 1.3 \% \mathrm{NaHCO}_{3} 2 \mathrm{ml}$ ), and then centrifuged at 1,500 rpm (05PR-22, Hitachi, Tokyo) for $5 \mathrm{~min}$. Following epididymal plasma removal, the sperm were rewashed, and kept in ice cold sperm-Ringer solution. The motility and viability of spermatozoa was observed immediately after removal, and after 2 and $4 \mathrm{hr}$ by conventional vital dye staining.

\section{Reagents}

$\left.{ }^{125} \mathrm{I}\right)-\mathrm{Tyr}-\mathrm{MT}$ antigen $\left({ }^{125} \mathrm{I}-\mathrm{MT}\right)$, unlabeled rabbit MT-II antigen (Sigma Chem. Co., St. Louis, MO, USA), normal rat serum (Sigma Chem. Co.), anti-MT-I antibody (Umeyama et al. 1987; Suzuki et al. 1991), immunogold conjugate (goat anti-rabbit IgG: $20 \mathrm{~nm}$, BioCell Research Laboratories, Cardiff, England) and $10 \%$ buffered formalin solution were used. ${ }^{125} \mathrm{I}-\mathrm{MT}$ was prepared by reacting rat MT-II with Tyr-MBS (M-maleimidobenzoyl-N-hydroxy succimide) and radioiodinated by chloramine $\mathrm{T}$ method. The conformation of labeled MT was well preserved compared with direct Bolton-Hunter iodination of MT, and MT binding with anti-MT antibody which recognizes the $\mathrm{NH}_{2}$-terminal epitope of MT was not affected (Nakajima et al. 1992).

\section{$M T$ binding to sperm}

MT binding reactions were performed at room temperature (R.T.) for $2 \mathrm{hr}$ with and without $4 \%$ normal rat serum per tube at various sperm dilutions (100 $\mu \mathrm{l}$ ), by adding $100 \mu \mathrm{l}$ of 10 -fold diluted ${ }^{125} \mathrm{I}-\mathrm{MT}$. The MT binding assay procedure outlined below was used with $4 \%$ normal rat serum per tube to inhibit 
non-specific ${ }^{125} \mathrm{I}-\mathrm{MT}$ binding to sperm.

Binding studies of ${ }^{125} \mathrm{I}-\mathrm{MT}$ ( $50 \mu 1$ of 5 -fold dilution) and sperm $\left(50 \mu 1,5 \times 10^{5}\right.$ cells per tube) were carried out at $0^{\circ} \mathrm{C}, \mathrm{R} . \mathrm{T}$., and $37^{\circ} \mathrm{C}$ for 0 time, 2 and $4 \mathrm{hr}$ with $4 \%$ normal rat serum in the test tubes shaking gently. Competition binding experiments using unlabeled MT-II and $2 \times 10^{5}$ spermatozoa per tube were performed. Displacement curves were obtained with ${ }^{125} \mathrm{I}-\mathrm{MT}(0.6$ to $41.3 \mathrm{nM})$ in the presence of increasing amounts of unlabeled MT-II $(5 \mathrm{mg} / \mathrm{ml})$ at R.T. for $4 \mathrm{hr}$. The competitive effect was studied using rabbit MT-II $(0.063$ to $1.0 \mathrm{mg} / \mathrm{ml})$ for 4 $\mathrm{hr}$ incubation at R.T. The inhibition of ${ }^{125} \mathrm{I}-\mathrm{MT}$ binding to spermatozoa by anti-MT antiserum was performed by adding the diluted antiserum (400- to 122 , 400 -fold dilution) to ${ }^{125} \mathrm{I}-\mathrm{MT}$ solution and incubated for $10 \mathrm{~min}$ before mixing with the spermatozoa. Its reaction was then carried out at R.T. for $2 \mathrm{hr}$.

All reactions were stopped by adding ice-cold sperm-Ringer solution and the tubes were immediately centrifuged at 3,000 rpm (CD-100R; Tomy Seiko Co., Ltd., Tokyo) for $10 \mathrm{~min}$ at $4^{\circ} \mathrm{C}$. Supernatant fluids were removed and sperm were washed twice. Supernatant fluids were removed and the ${ }^{125} \mathrm{I}$ radioactivity of the spermatozoa was counted by an automatic gamma counter (ARC-600; Aloka, Tokyo).

Fractionation of the spermatozoa $\left(1 \mathrm{ml}, 6 \times 10^{7}\right.$ cells per $\left.1 \mathrm{ml}\right)$ by sucrose gradient (10-70\%) centrifugation was performed. After incubation with ${ }^{125} \mathrm{I}-\mathrm{MT}$ $(1 \mathrm{ml})$ at $37^{\circ} \mathrm{C}$ for $4 \mathrm{hr}$, the spermatozoa was washed three times, followed by sonication for $2 \mathrm{~min}$ with Noridate $(0.5 \%$ ) (Sigma Chem. Co.), treatment with 0.1 $\mathrm{ml}$ of PBS with $20 \%$ rat serum, and centrifuged at $10,000 \mathrm{rpm}$ for $2 \mathrm{hr}$ at $20^{\circ} \mathrm{C}$. The rat spermatozoa were reported to be cleaved by sonication (Sonifer Model 200, Branson Co., CA, USA) with Noridate treatment to yield free heads and tails (Millette et al. 1973).

\section{Transmission electron microscopical observation}

The spermatozoa washed with sperm-Ringer solution were incubated with rat MT antigen, MT antigen preabsorbed with anti-MT antibody (100 dilution), and normal rat serum (10\%) for $2 \mathrm{hr}$ at $4^{\circ} \mathrm{C}$. Rat MT-II antigen was used as a labeled MT antigen of decreased radioactivity. After washing with $0.1 \mathrm{M}$ phosphate buffer ( $\mathrm{pH} \mathrm{7.4)} \mathrm{three} \mathrm{times,} \mathrm{the} \mathrm{spermatozoa} \mathrm{were} \mathrm{reacted} \mathrm{with} \mathrm{anti-MT} \mathrm{antibody}$ (200 dilution) (0.1M PBS, $0.1 \% \mathrm{BSA}$ ) for $2 \mathrm{hr}$ at $4^{\circ} \mathrm{C}$. After washing with PBS three times, it was treated with a gold labeled secondary antibody (50-1 dilution) for $30 \mathrm{~min}$ and then washed with PBS. The spermatozoa were fixed in $2 \%$ glutaraldehyde solution (0.1M buffered cacodylic acid, $\mathrm{pH} \mathrm{7.4)}$ for $1 \mathrm{hr}$ at $4^{\circ} \mathrm{C}$. After washing with PBS, the specimen was dehydrated in graded concentrations of ethanol and embedded in Lowicry $\mathrm{K} 4 \mathrm{M}$ resin. Ultrathin sections were observed with a transmission electron microscope (TEM) (1200EX; JEM, Tokyo) after electron staining with uranyl acetate and lead citrate. 


\section{Autoradiography by optical and transmission electron microscope}

The spermatozoa were reacted with ${ }^{125} \mathrm{I}-\mathrm{MT}$ at R.T. for $2 \mathrm{hr}$, fixed by adding $10 \%$ buffered formalin for $30 \mathrm{~min}$, and then washed three times with ice cold sperm-Ringer solution. They were mounted on a poly-L-lysine coated glass slide, and dried. The glass slides mounted with sperm were coated with autoradiographic emulsion (NR-M2; Konica, Tokyo) by dipping and placed in a cassette in a dark room at $4^{\circ} \mathrm{C}$. After three weeks, glass slides were developed, stained by hematoxylin and eosin, and examined under an optical microscope. The specificity of ${ }^{125} \mathrm{I}-\mathrm{MT}$ binding to the spermatozoa was confirmed in a prior absorption of ${ }^{125} \mathrm{I}-\mathrm{MT}$ with either anti-MT antibody, or with an excess of pure rabbit liver MT antigen, and omission of ${ }^{125} \mathrm{I}-\mathrm{MT}$ from the procedure.

For electron microscopic autoradiography, the spermatozoa reacted with ${ }^{125} \mathrm{I}-\mathrm{MT}$ (described above) were washed and fixed in $2.5 \%$ paraformaldehyde and $2 \%$ glutaraldehyde mixture solution (0.1 M PBS, $\mathrm{pH} 7.2)$ for $2 \mathrm{hr}$ at $4^{\circ} \mathrm{C}$. They were then washed in the same buffer solution for 30 min, postfixed in $1 \%$ osmium tetroxide in the same buffer for $2 \mathrm{hr}$, dehydrated in graded concentrations of acetone, and embedded in epoxy resin. Ultrathin sections were stained with uranyl acetate, covered with NR-HK2 emulsion (Sakura, Tokyo) by dipping, exposed for 4-6 weeks at $4^{\circ} \mathrm{C}$, developed in Fuji Korectol developer (Fuji, Tokyo) for $3 \mathrm{~min}$ at $18^{\circ} \mathrm{C}$, stained with lead citrate, and observed by TEM. The specificity of ${ }^{125} \mathrm{I}-\mathrm{MT}$ binding to the spermatozoa was tested by same procedure described for the optical microscope.

\section{RESULTS}

\section{Motility and viability of the spermatozoa}

Immediately after removal from the epididymal tail, the motility and viability of spermatozoa was shown to be more than $90 \%$. After washing with spermRinger solution, the motility was decreased to less than $10 \%$ in ice cold solution after 2 and $4 \mathrm{hr}$, but the viability was more than $50 \%$ at the end of the experiments.

\section{Characteristics of ${ }^{125} I-M T$ binding to the spermatozoa}

${ }^{125} \mathrm{I}-\mathrm{MT}$ binding to the spermatozoa was shown to decrease with addition of $4 \%$ normal rat serum, indicating some non-specific binding. The effects of temperature $\left(0^{\circ} \mathrm{C}, \mathrm{R} . \mathrm{T}\right.$. and $\left.37^{\circ} \mathrm{C}\right)$ and incubation time on total ${ }^{125} \mathrm{I}-\mathrm{MT}$ binding to the rat spermatozoa showed that higher binding was observed at $37^{\circ} \mathrm{C}$ for $4 \mathrm{hr}$, while lower temperature showed less binding. The total binding reaction was temperature and time dependent (Fig. 1). Affinity constants of the binding reaction by Scatchard plot analysis indicated that labeled MT antigen bound to the spermatozoa in two forms, namely, a middle affinity $\left(\mathrm{Kdl}=2 \times 10^{-9} \mathrm{M}\right)$ and a low affinity $\left(\mathrm{Kd} 2=1 \times 10^{-8} \mathrm{M}\right)$ (Fig. 2). MT binding to the spermatozoa was 


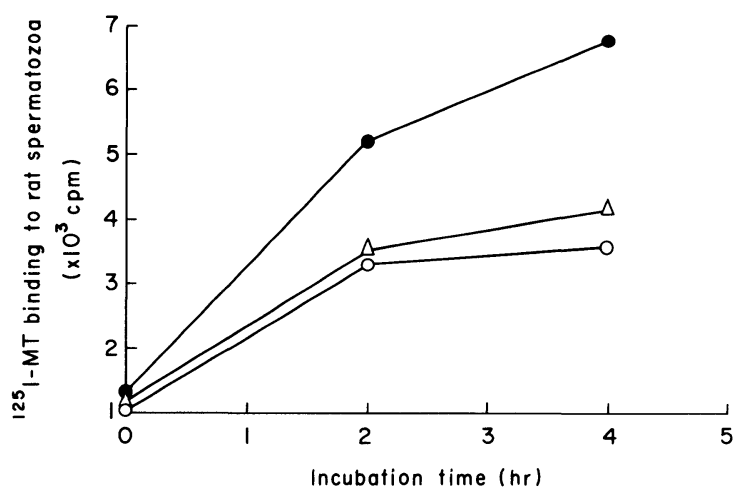

Fig. 1. Effect of temperature on Total ${ }^{125}$ I-MT binding to the spermatozoa. Total binding reactions were temperature and incubation time dependent. Sperm content, $50 \mu \mathrm{l}$ of $5 \times 10^{5}$ cells per tube: ${ }^{125} \mathrm{I}$-MT content, $50 \mu 1$ of 5 -fold dilution.

$\mathrm{O}-\mathrm{O}, 0^{\circ} \mathrm{C} ; \triangle-\triangle$, room temperature; $\bullet-37^{\circ} \mathrm{C}$.

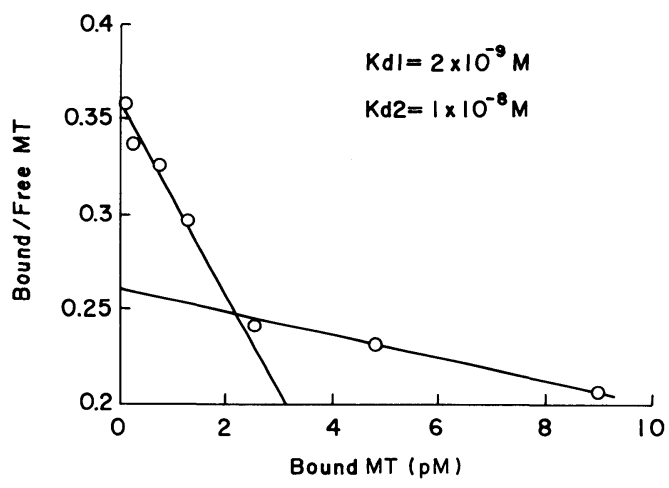

Fig. 2. Affinity constants of ${ }^{125} \mathrm{I}-\mathrm{MT}$ to the rat spermatozoa. Sperm content, 200 $\mu \mathrm{l}$ of $1 \times 10^{6}$ cells per tube: MT-II concentration, $5 \mathrm{mg} / \mathrm{ml} . \quad \mathrm{Kd} 1=2 \times 10^{-9} \mathrm{M}$; $\mathrm{Kd} 2=1 \times 10^{-8} \mathrm{M}$.

estimated to have specific and non-specific components. The specific binding sites were 840 sites per cell and the non-specific binding sites, which were a main binding form, were over 10,000 sites per cell. Competitive inhibition was studied using rabbit MT-II, showing a slight inhibition of ${ }^{125} \mathrm{I}-\mathrm{MT}$ binding to the rat spermatozoa in $4 \mathrm{hr}$ incubation at R.T. (Fig. 3). This data suggested that MT binding form to the spermatozoa was mainly non-specific. ${ }^{125} \mathrm{I}-\mathrm{MT}$ binding to the spermatozoa showed dose-dependent inhibition by anti-MT antibody, that is, 100 times diluted anti-MT antiserum in the reaction mixture completely inhibited the binding containing both specific and non-specific forms (Fig. 4). 


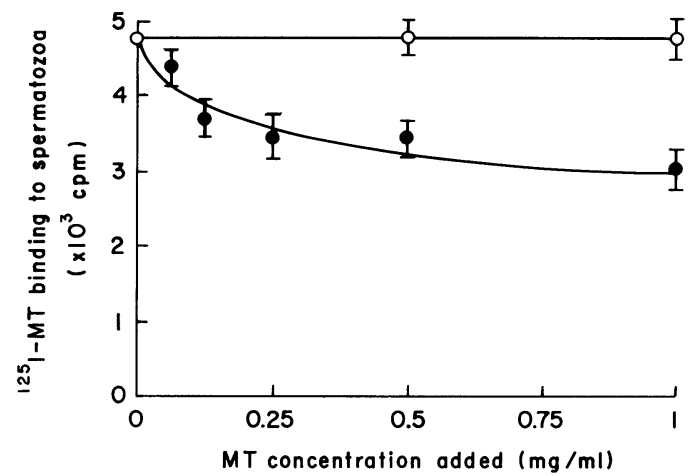

Fig. 3. Competitive effect of MT added on ${ }^{125} \mathrm{I}-\mathrm{MT}$ binding to the rat spermatozoa. The cold inhibition effect of rabbit MT-II was shown slightly.

$\bigcirc-\mathrm{O}$, control; $\bullet-\longrightarrow \mathrm{MT}$ antigen added $(n=3)$.

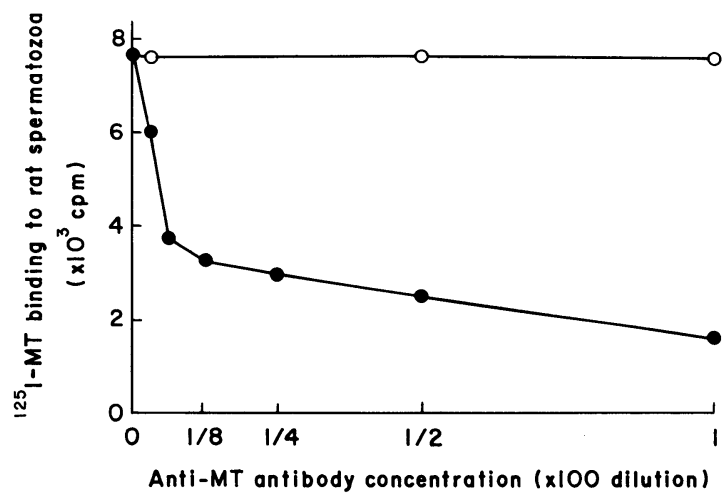

Fig. 4. Effect of anti-MT antibody on ${ }^{125} \mathrm{I}-\mathrm{MT}$ binding to the rat spermatozoa. 100 times diluted anti-MT antibody completely inhibited the reaction. Sperm content, $100 \mu \mathrm{l}$ of $5 \times 10^{5}$ cells per tube; ${ }^{125} \mathrm{I}$-MT content, $50 \mu \mathrm{l}$ of 5 -fold dilution; $\bigcirc-\mathrm{O}$, control; $\bullet \longrightarrow$, anti-MT antibody added.

\section{Binding site of ${ }^{125} I-M T$ to rat spermatozoa by sucrose density gradient}

The localization of ${ }^{125} \mathrm{I}-\mathrm{MT}$ bound to the spermatozoa $\left(4 \mathrm{hr}, 37^{\circ} \mathrm{C}\right)$ was studied by fractionating the rat spermatozoa, after cleavage of both heads and tails by sonication with Noridate. Fig. 5 shows that the highest concentration of ${ }^{125} \mathrm{I}-\mathrm{MT}$ was detemined to have two peaks at the heaviest sucrose density fractions $(60 \%$ and $>60 \%$ ). An optical microscopic observation showed that the peak at $>60 \%$ density contained mainly heads of the spermatozoa, and the other contained mainly tails and partly heads of the spermatozoa. A small peak (about 14\%) was shown at the lightest density. This result suggested that labeled MT was localized in both heads and tails. 


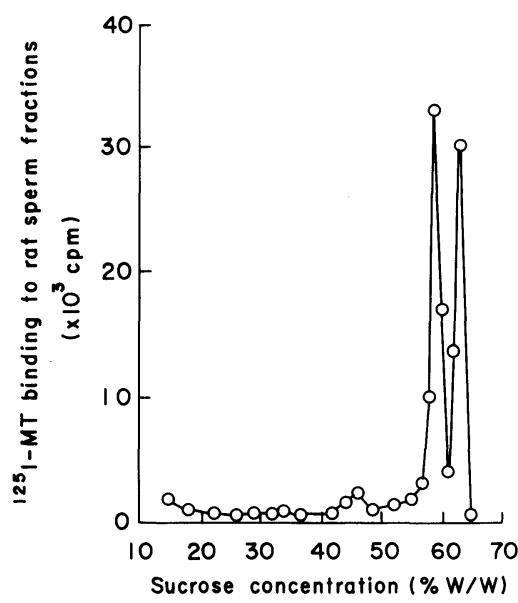

Fig. 5. ${ }^{125} \mathrm{I}-\mathrm{MT}$ binding profile to rat sperm fractions by sucrose gradient centrifugation. Two peaks were observed at heaviest sucrose density fraction which mainly contained the sperm head.

\section{TEM observation by indirect method using a gold labeled antibody}

The spermatozoa treated with MT antigen showed that gold particles were localized in the cell membrane of the head and tail (Fig. 6c, 6d, 6e). Many gold particles were observed in the head and the proximal portion of the tail. Particles in the distal portion of the tail were fewer compared with those in the proximal portion of the tail. The spermatozoa treated with MT antigen preabsorbed with anti-MT antibody did not have any particles in the cell membrane of the head and tail (Fig. 6a, 6b). The spermatozoa reacted with normal rat serum showed a few particles in the cell membrane of the head and proximal portion of the tail in some spermatozoa (data not shown). Exogenous MT antigen was thought to mainly bind to the cell membrane of the head and tail.

\section{Autoradiography by optical microscope and TEM}

By optical microscopy, grains in the spermatozoa treated with labeled MT were observed mainly in the head and the proximal portion of the tail (Fig. 7). There were few grains in the distal portion of the tail. The spermatozoa treated with labeled MT preabsorbed with MT antibody, and with excess MT antigen had few or no grains in the head and tail (data not shown). This finding was the same as described above by TEM observation using an indirect method. By TEM observation, grains in the spermatozoa treated with labeled MT were identified mainly in the cell membrane of the head and tail, and a few were localized in the nucleus (Fig. 8a). There were almost no grains in the spermatozoa treated with ${ }^{125} \mathrm{I}-\mathrm{MT}$ preabsorbed with antibody (Fig. 8b), ${ }^{125} \mathrm{I}-\mathrm{MT}$ with excess MT antigen, and when ${ }^{125} \mathrm{I}-\mathrm{MT}$ was omitted from the procedure. Electron microscopic autoradio- 
T. Suzuki et al.

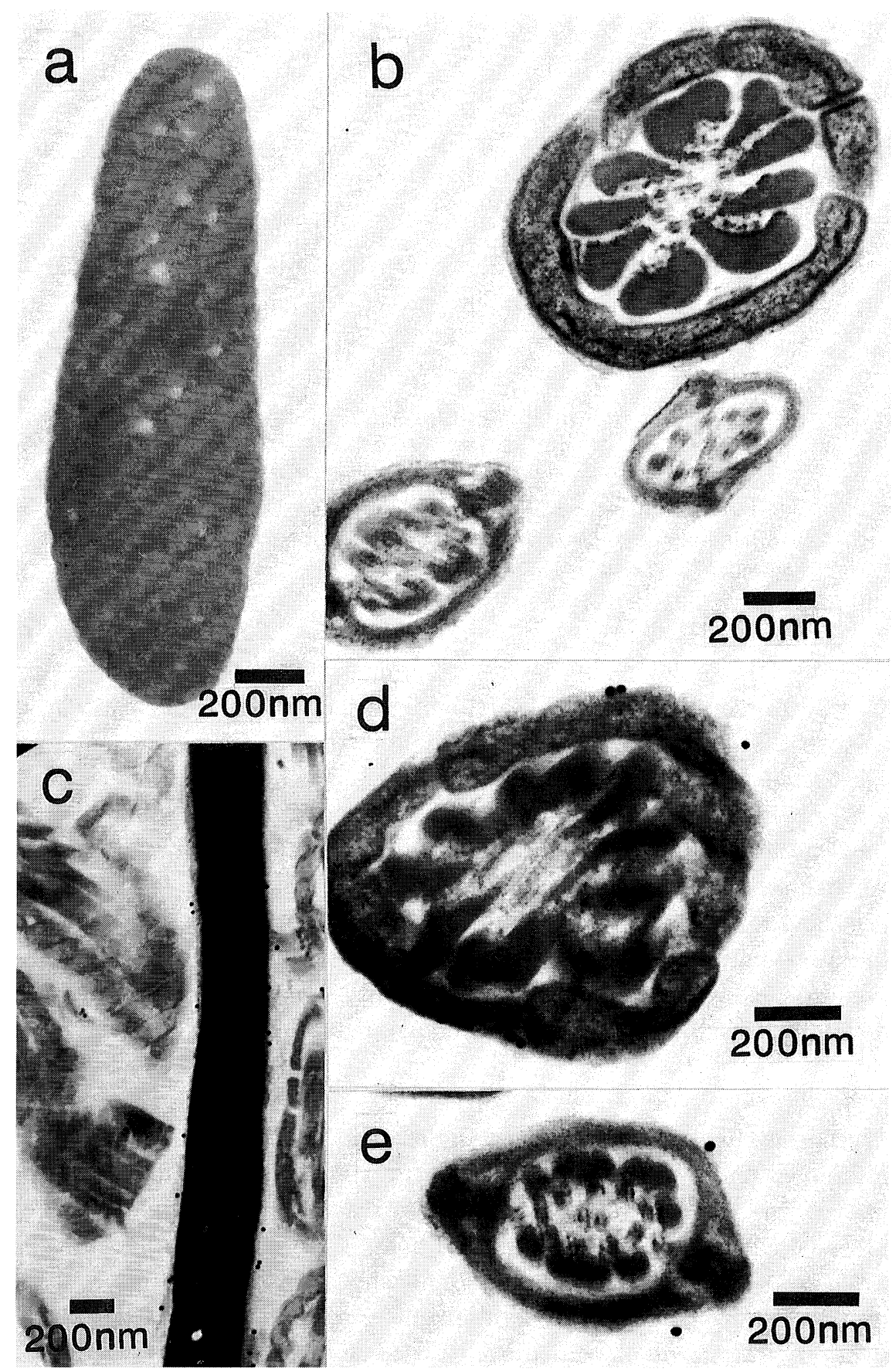

Fig. 6. 


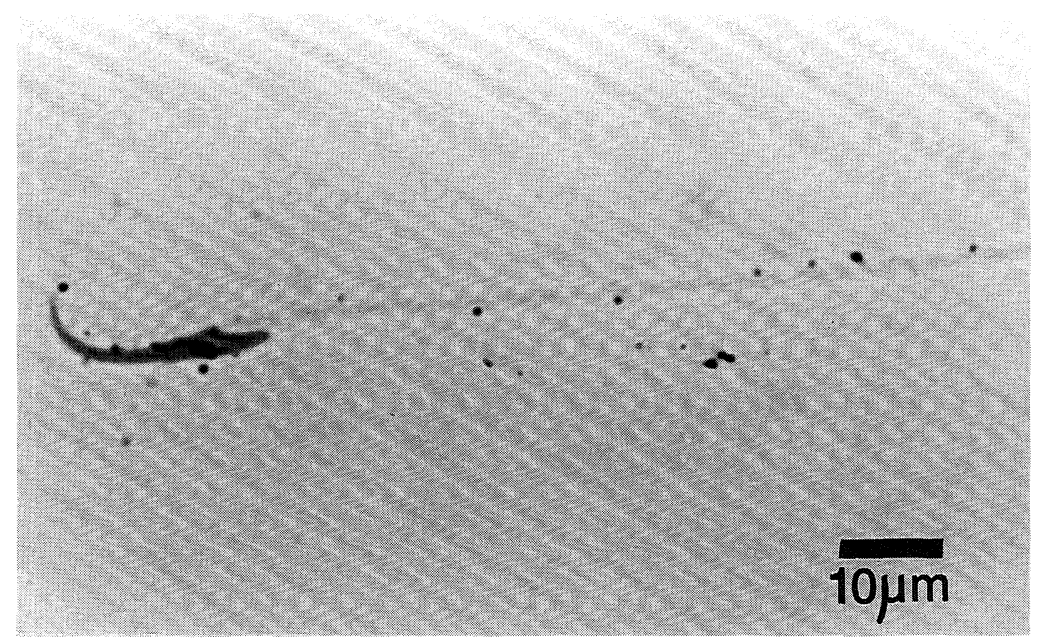

Fig. 7. Autoradiography by an optical microscopy. Grains of labeled MT were shown in the sperm head and the proximal portion of tail. $(\times 1,000)$

graphy showed that labeled MT mainly bound to the cell membrane.

\section{Discussion}

MT was identified in rat and human prostatic tissue (Bataineh et al. 1986; Umeyama et al. 1987; Suzuki et al. 1991). In the rat prostate, high MT concentration was seen in the lateral prostate, which has a high zinc concentration (Gunn and Gould 1957; Muntzing et al. 1977; Bataineh et al. 1986; Umeyama et al. 1987; Suzuki et al. 1991). In human prostate, a high MT concentration in tissues of the peripheral zone, which also exhibit high zinc concentration has been described (Mawson and Fisher 1952; Suzuki et al. 1991). MT secreted into the prostatic fluid by prostatic epithelial cells we have recently found using radioimmunoassay. MT concentration in prostatic fluid was lower in acute prostatitis, and higher in benign prostatic hypertrophy and chronic prostatitis than in normal patients (Suzuki et al. 1992). Zinc in seminal fluid has been reported to mainly derive from the prostate gland (Anderson and Fair 1976). MT is known to bind zinc (Vallee 1959; Kägi and Vallee 1960), but the function of MT in the male genital tract has not been reported.

In the present study, labeled MT showed high and low affinity binding to spermatozoa. Its binding was inhibited by adding anti-MT antibody solution,

Fig. 6. Transmission electron microscopical observation of MT binding to the rat spermatozoa by indirect method. $a(\times 33,000)$ and $b(\times 26,000)$; control. The spermatozoa was reacted with MT antigen preabsorbed with anti-MT antibody. Gold particles were not observed. c $(\times 50,000), d(\times 50,000)$, and e $(\times 50,000)$; The spermatozoa was reacted with MT antigen. Gold particles were observed in the membrane of the head and the proximal portion of tail, and a few were at the distal portion of tail. 


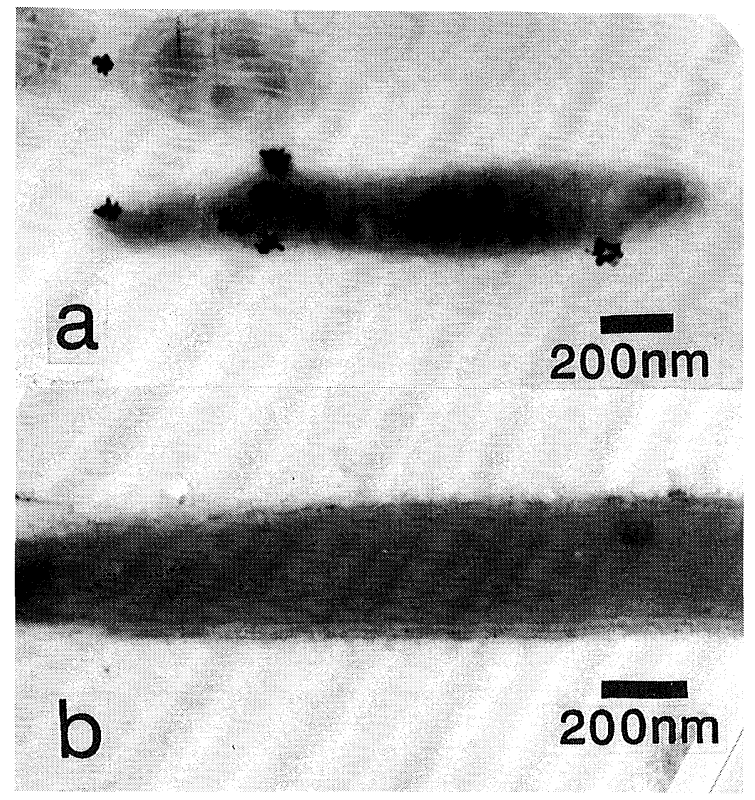

Fig. 8. Autoradiography by an electron microscopy. a; The spermatozoa was reacted with ${ }^{125} \mathrm{I}-\mathrm{MT}$. Grain of labeled MT were observed mainly in the cell membrane and partly in the nucleus. $(\times 20,000) \quad b$; control. The spermatozoa was reacted with labeled MT preabsorbed with anti-MT antibody. Grains were not observed in the head. $(\times 20,000)$

suggesting that MT has both specific and non-specific binding sites on the spermatozoa. Observation by TEM using an indirect immunological method showed that the MT binding site was mainly the cell membrane of the head and the proximal portion of the tail. Radiolabeled MT used in this study has the native conformation conserved as much as possible and reacts with the MT antibody which recognizes the $\mathrm{NH}_{2}$-terminal (Nakajima et al. 1992). During the maturation of spermatozoa in the epididymis, it is well known that many proteins are adsorbed to the cell membrane (Faye et al. 1980; Jones et al. 1981). The binding site of MT is of course not known, but this result suggested that MT binding to the spermatozoa is mainly a nonspecific form and partly a specific form.

Another important finding was that exogenous labeled MT was localized in the sperm nucleus. The spermatozoa used in this study had less than $10 \%$ of motility, but the viability was more than $50 \%$ after being washed and kept in ice cold sperm-Ringer solution. Some labeled MT or free labeled iodine could permeate through the cell membrane into the nucleus, but the labeled MT was thought to actively enter the nucleus because the grains in the nucleus were nearly nonexistent in the control specimens by an electron autoradiography. MT has been reported to be mainly localized in the cytoplasm but also in the nucleus by several investigators (Panemangalore et al. 1983; Umeyama et al. 1987; Nishi- 
mura et al. 1990; Suzuki et al. 1991). Nishimura et al. (1990) reported that MT was localized in the nucleus of rat sperm in the testis by an immunohistochemical study. Also, the level of MT mRNA is maintained at a high level in the spermatid in the mouse, but that in the mature sperm cells it is low (De et al. 1991). The present study suggests that epididymal spermatozoa binds MT secreted from the prostate gland at the cell membrane, and MT plays a biological role to the spermatozoa. The entrance of exogenous MT into the nucleus must be carefully investigated in the future.

\section{References}

1) Anderson, R.U. \& Fair, W.R. (1976) Physical and chemical determinations of prostatic secretion in benign hyperplasia, prostatitis, and adenocarcinoma. Invest. Urol., 14, 137-140.

2) Bataineh, Z.M., Heidger, P.M., Thompson, S.A. \& Timms, B.G. (1986) Immunocytochemical localization of metallothionein in the rat prostate gland. Prostate, 9, 397410 .

3) De, S.K., Enders, G.C. \& Andrews, G.K. (1991) High levels of metallothionein messenger RNAs in male germ cells of adult mouse. Mol. Endocrinol., 5, 628-636.

4) Faye, J.C., Duguet, L., Mazzuca, M. \& Bayard, F. (1980) Purification, radioimmunoassay, and immunohistochemical localization of a glycoprotein produced by the rat epididymis. Biol. Reprod., 23, 423-432.

5) Gunn, S.A. \& Gould, T.C. (1957) Hormone interrelationships affecting the selective uptake of ${ }^{65} \mathrm{Zn}$ by the dorso-lateral prostate of the hypophysectomized rat. $J$. Endocrinol., 16, 18-27.

6) Jones, R., Pholpramool, C., Setchell, B.P. \& Brown, C.D. (1981) Labelling of membrane glycoproteins on rat spermatozoa collected from different regions of the epididymis. Biochem. $J$., 200, 457-460.

7) Kägi, J.H.R. \& Vallee, B.L. (1960) Metallothionein: A cadmiun- and zinc- containing protein from equine renal cortex. J. Biol. Chem., 235, 3460-3465.

8) Margoshes, M. \& Vallee, B.L. (1957) A cadmium protein from equine kidney cortex. J. Am. Chem. Soc., 799, 4813-4814.

9) Marmar, J.L., Katz, S., Praiss, D.E. \& DeBenedictis, T.J. (1975) Semen zinc levels in infertile and postvasectomy patients and patients with prostatitis. Fertil. Steril., 26, 1057-1063.

10) Mawson, C.A. \& Fisher, M.I. (1952) The occurrence of zinc in the human prostate gland. Can. J. Med. Sci., 30, 336-339.

11) Millette C.F., Spear, P.G., Gall, W.E. \& Edelman, G.M. (1973) Chemical dissection of mammalian spermatozoa. J. Cell Biol., 58, 662-675.

12) Muntzing, J., Kirdani, R., Murphy, G.P. \& Sandberg, A.A. (1977) Hormonal control of zinc uptake and binding in the rat dorsolateral prostate. Invest. Urol., 14, 492-495.

13) Nakajima, K., Suzuki, K., Otaki, N. \& Kimura, M. (1992) Epitope mapping of metallothionein antibodies. In: Methods in Enzymology, Vol. 205, edited by J.F. Riordan \& B.L. Vallee, Academic Press Inc., San Diego, pp. 174-189.

14) Nishimura, H., Nishimura, N. \& Tohyama, C. (1990) Localization of metallothionein in the genital organs of the male rat. J. Histochem. Cytochem., 38, 927-933.

15) Panemangalore, M., Banerjee, D., Onosaka, S. \& Cherian, M.G. (1983) Changes in the intracellular accumulation and distribution of metallothionein in rat liver and kidney during postnatal development. Dev. Biol., 97, 95-102.

16) Suzuki, T., Umeyama, T., Ohma, C., Yamanaka, H., Suzuki, K., Nakajima, K. \& Kimura, M. (1991) Immunohistochemical study of metallothionein in normal and 
benign prostatic hyperplasia of human prostate. Prostate, 19, 35-42.

17) Suzuki, T., Yamanaka, H., Tamura, Y., Nakajima, K., Kanatani, K., Kimura, M. \& Otaki, N. (1992) Metallothionein of prostatic tissues and fluids in rats and humans. Tohoku J. Exp. Med., 166, 251-257.

18) Umeyama, T., Saruki, K., Imai, K., Yamanaka, H., Suzuki, K., Ikei, N., Kodaira, T., Nakajima, K., Saitoh, H. \& Kimura, M. (1987) Immunohistochemical demonstration of metallothionein in the rat prostate. Prostate, 10, 257-264.

19) Vallee, B.L. (1959) Biochemistry, physiology and pathology of zinc. Physiol. Rev., 39, 443-490.

20) Waalkes, M.P., Donovan, M.P. \& Thomas, J.A. (1982) Cadmium-induced prostate metallothionein in the rabbit. Prostate, 3, 23-25. 